\title{
PARTICIPAÇÃO CIDADÃ ONLINE: O POTENCIAL DELIBERATIVO DOS GRUPOS DA REBAL21
}

\author{
ALYSSON BRUNO ASSUNÇÃO \\ Rio de Janeiro, RJ - Brasil \\ E-mail: alyssonassuncao@hotmail.com
}




\section{PARTICIPAÇÃO CIDADÃ ONLINE: O POTENCIAL DELIBERATIVO DOS GRUPOS DA REBAL21}

Resumo: $O$ artigo aborda a utilização de novas TICs para favorecer a troca pública de idéias, analisando aspectos qualitativos e quantitativos de grupos de discussão online da rede social Rebal21, baseada na plataforma Ning. Os resultados sugerem que redes sociais na internet como essa podem possibilitar trocas discursivas qualificadas e aprendizado dos usuários sobre de temas de interesse público.

Palavras chave: internet; democracia digital; grupos online de discussão.

PARTICIPACIÓN CIUDADANA EN LÍNEA: EL POTENCIAL DELIBERATIVO DE LOS GRUPOS DE LA RED REBAL21

Resumen: El artículo analiza el uso de las TIC para promover el intercambio público de ideas, con análisis de los aspectos cualitativos y cuantitativos de los grupos de discusión en línea en la red social Rebal21, basada en la plataforma Ning. Los resultados sugieren que estos sitios pueden facilitar los intercambios discursivos calificados y de aprendizaje de los usuarios sobre cuestiones de interés público.

Palabras clave: internet, democracia digital, grupos de discusión en línea.

CITIZEN PARTICIPATION ONLINE: THE DELIBERATIVE POTENTIAL OF GROUPS FROM REBAL21

Abstract: The article discusses the use of ICTs to promote public exchange of ideas, analyzing qualitative and quantitative aspects of online discussion groups Rebal21 social network, based on the Ning platform. The results suggest that social networking sites like this can facilitate discursive exchanges qualified and learning from users about issues of public interest.

Keywords: internet, digital democracy, online discussion groups. 


\section{INTRODUÇÃO}

Tendências recentes de investigação nas Ciências da Comunicação, interessadas em educação cívica e política dos cidadãos, vêm ressaltando o impacto da utilização dos meios digitais de comunicação em rede no contexto da democracia contemporânea. O potencial desse tipo de ferramenta pode ser enquadrados segundo dois fatores: (a) a diminuição de custos e dificuldades técnicas e logísticas para publicação, resultando em maior pluralização política e igualdade de condições para os atores sociais difundirem discursos; e (b) ampliação das possibilidades para os cidadãos interagirem em redes, viabilizando iniciativas de governança e cidadania eletrônicas (ALDÉ, 2011).

Parte desses estudos sobre democracia digital se concentram usos que diversos atores fazem da rede e as consequências práticas que ela traz para os processos políticos, ao possibilitar abordagem e deliberação sobre temas de interesse público. (MAIA, 2008; MARQUES, 2010; MIOLA, 2011). Grupos de discussão, petições e consultas públicas podem prover ao cidadão um papel do qual não goza nos meios de comunicação de massa, pois passa de simples consumidor a co-protagonista.

Esse trabalho procura desenvolver uma reflexão sobre as possibilidades de os cidadãos exercerem participação política online, ao investigar à participação e potencial de deliberação online a partir da análise de quatro grupos de discussão da Rede Brasileira de Agendas 21 Locais - Rebal 21 (rebal21.ning.com). Estima-se que, atualmente, as redes sociais, sejam gerais (como Orkut e Facebook) ou específicas, como é caso do Ning (SANTAELLA \& LEMOS, 2010), constituem valioso ambiente para discussão dos processos políticos, podendo funcionar ao mesmo tempo como "eco" de dinâmicas sociais e como gerador de debates.

\section{DESENVOLVIMENTO}

O trabalho combinou analise qualitativa - realizada combinando metodologia de "navegação orientada"'(SILVA, 2009, p. 157) na rede com a aná-

\footnotetext{
1 Essa metodologia se baseia numa abordagem qualitativa e quantitativa, na qual a coleta de dados se dá por meio de técnicas de observação direta nos sites escolhidos para a pesquisa, e por testes e simulações das ferramentas online. São obedecidos critérios para navegação pelas páginas, uma vez que existe um grande quantitativo de links dispostos numa infinidade de páginas interligadas. Também define a forma de qualificar os objetos
} 
lise de conteúdo² das mensagens postadas (BARDIN, 1998) nesses grupos. Antes de passar análise propriamente dita e aos resultados obtidos, retomaremos discussões da literatura sobre internet, democracia digital, participação e deliberação online.

\subsection{Internet, esfera pública e democracia digital}

O debate em torno da democracia na contemporaneidade envolve, pelo menos, duas concepções do termo: a primeira se define em torno do conjunto de procedimentos para formar governos e garantir rotatividade no poder. Outra concepção, contra-hegemônica, entende a democracia como um processo de realização de instâncias deliberativas capazes de exercer algum tipo de influência sobre o processo decisório (SANTOS \& AVRITZER, 2009). A última posição remete a uma noção de política enquanto atividade contínua - diz respeito a todos os cidadãos e extrapola o exercício do voto - que é possibilitada por interações discursivas. O espaço público onde ocorrem essas interações, diz Hanna Arendt (1995), marca a importância da comunicação intersubjetiva através da qual as opiniões e julgamentos se constituem.

Nesse sentido, a esfera pública, tal como discutida por Jungem Habermas (1997), preza as noções de visibilidade e pluralidade de atores e perspectivas que, por meio da interação discursiva, produzem entendimentos compartiIhados e atuam como uma "rede adequada para a comunicação de conteúdos, tomadas de posição e opiniões, na qual os fluxos comunicacionais são sintetizados a ponto de se condensarem em opiniões públicas enfeixadas em temas específicos" (HABERMAS, 1997, p.92). Assim, o conceito de esfera pública pode ser entendido não como uma coisa única, mas como uma multiplicidade de espaços de interação, formados por diversos segmentos sociais.

Com o advento da Internet passou-se a discutir os diversos fatores que fazem com que ela possa ser utilizada para fins mais democráticos, como a redução dos custos de participação política, o envolvimento de maior núme-

analisados, gerando amostras que podem viabilizar a produção de análises comparativas posteriores. Para maiores detalhes, ver a dissertação de doutorado de Sivaldo Silva (2009).

2 Para a realização da análise de conteúdo, as mensagens publicadas pelos usuários dos grupos foram compiladas em uma planilha de Microsoft Excel 2010. A análise foi realizada a partir de categoriais obtidas a partir de uma combinação de elementos oriundos de trabalhos semelhantes (DALHBERG, 2001; JENSEN, 2003; MARQUES, 2010; MIOLA, 2011), com algumas adaptações. 
ro de cidadãos nas discussões (embora o problema do acesso no contexto brasileiro não seja ignorado), e o fluxo de comunicação de cidadão para cidadão. Sem enfatizar a dimensão tecnológica, cabe ainda ressaltar que ferramentas online que inicialmente eram "monomodais" (e-mails, chats, grupos de discussão) foram incorporadas em outras "multimodais", com maior integração e congregando a mobilidade (SANTAELLA \& LEMOS, 2008, p.58).

Para Rousiley Maia (2008), esse é um potencial inédito, por meio do qual diferentes instâncias da sociedade, incluindo representantes do governo, podem trocar informações e debater de maneira direta, sem entraves burocráticos. Esse tipo de ferramenta permitiria a formação de um ambiente informativo denso com condições para a participação democrática e deliberação sobre temas de interesse comum de uma forma racional, não-coercitiva, e buscando contemplar perspectivas distintas, de forma que sejam compreendidas e aceitas pelos outros participantes.

Ao descrever as condições necessárias para a democracia digial, Coleman e Blumber (2009) utilizam uma tipologia útil das estratégicas de estimular a participação pública a partir das possibilidades da internet, como disseminar informações, realização de consultas públicas, exploração e visualização de novas propostas, julgamento e deliberação em conjunto, suporte e tomada de decisões. Os autores reconhecem a dificuldade de atender às condições ideias para deliberação na atualidade, e apontam para a necessidade de abordagens tecnológicas que favoreçam a tomada de decisões de forma dinâmica e auto-sustentavel (COLEMAN \& BLUMBER, 2009, p.30), entendendo a esfera pública é mais como fator conector, em vez de integrador (p.179).

Pensando a questão da participação e deliberação no atual contexto, Lincoln Dahlberg (2001, p.623), seria possível explorar o potencial dessas ferramentas de comunicação online de forma a "estender a esfera pública", que o autor desenha a partir das teorias da ação comunicativa, ética do discurso e da deliberação de Habermas. Seriam necessários alguns requisitos fundamentais:

* Troca de razões fundamentadas pratica e moralmente validas. Deliberação envolve engajar-se em crítica recíproca de posições normativas que racionalmente fundamentadas, ao invés de alegações.

* Reflexividade. Os participantes devem examinar criticamente seus valores culturais, suposições e interesses, bem como o contexto social mais amplo. 
* Reciprocidade. Os participantes devem tentar compreender o argumento da a perspectiva do outro. Isso requer um compromisso de um diálogo permanente com a diferença em que os interlocutores respeitosamente ouvir uns aos outros.

* Sinceridade. Cada participante deve fazer um esforço sincero para fornecer todas as informações relevantes para o problema particular em consideração, incluindo informações sobre as intenções, interesses, necessidades e desejos.

* Inclusão e igualdade discursiva. Cada participante afetado pela pretensões de validade está igualmente no direito de introduzir e questionar qualquer afirmação. A inclusão pode ser limitada por restrições formais ou informais de acesso e por desigualdades no discurso, onde alguns dominam o discurso e os outros lutam para ter suas vozes ouvidas.

* Autonomia frente ao Estado e ao poder econômico. O discurso deve ser impulsionado pelas preocupações dos cidadãos, e não por dinheiro ou poder administrativo.

Em relação ao conteúdo das mensagens, Jakob Jensen (2003) estabelece como principais variáveis para análise a forma - que consiste na pertinência ou relevância das mensagens trocadas, dentro da discussão realizada - e o diálogo - ou seja, se os participantes respondem uns aos outros ou trocam mensagens sem conexão. É importante ainda considerar o tom das mensagens (se é respeitoso ou não), a abertura dos participantes (assumindo suas identidades) e o conteúdo da argumentação.

\subsection{Participação democrática e deliberação na internet}

Vários são os exemplos relatados na literatura acerca das possibilidades e estratégicas para utilização da internet na viabilização da participação democrática. Chadwick (2006) destaca a Public Eletronic Network (PEN), fundada em Santa Mônica, em 1989, que combinava informação administrativa produzida pela prefeitura; dados de eventos culturais e entretenimento; lista compartilhada de endereços dos participantes; conferências moderadas pela prefeitura; serviços públicos (desde biblioteca a remoção de entulho); banco de dados e estatísticas da cidade. Embora não mais em atividade, a rede chegou a ter, em 1995, 7000 cadastrados e cerca de 400 participantes ativos.

Emblemático nesse panorama é o caso do projeto Minnesota E-De- 
mocracy (DALHBERG, 2001; CHADWICK, 2006), que desde 1994 desenvolve fóruns de discussão online. Os membros têm direitos e responsabilidades associadas a discussão aberta e pública, sendo um dos primeiros de fóruns online a debater amplamente sobre um processo eleitoral local. Em 2000 a lista Mn-Politics Discuss (MPD) tinha 400 assinantes - em 2011, são cerca de 560. O MPD tornou-se o modelo sobre o qual o projeto desenvolveu outros fóruns sobre questões políticas, e atualmente hospeda 30 grupos locais em 15 comunidades dos Estados Unidos, Reino Unidos, e Nova Zelândia.

Coleman e Blumber (2009) destacam Criador de Campanhas Comunitárias - site criado pelo Conselho da Cidade de Bristol, Reino Unido - que visa capacitar pessoas para acessar e utilizar novas ferramentas online, com foco em iniciativas locais. Tem quatro principais recursos: (a) o www.campaigncreator.org, com grupos de discussão para interessados trocarem experiências sobre promoção de campanhas e deliberação de assuntos de interesse público (com regras de conduta); (b) ferramenta para gerenciamento de campanhas online, focada no desenvolvimento de websites, e-newsletters, surveys e petições; (c) um guia de campanha, disponível para impressão; e (d) um coaching de campanha.

Sampaio, Maia e Marques (2010) realizam uma análise das trocas discursivas realizadas no fórum online do orçamento participativo digital (OPD) de Belo Horizonte, na qual se verificam que aspectos discursivos concernentes à reciprocidade e à reflexividade se mostraram relativamente escassos, mas é constatado o respeito pelos outros interlocutores, assim como a construção da justificativa dos pontos de vista.

Marques (2010) abordou os portais da Presidência da República e da Cãmera dos Deputados. No primeiro, a análise dos padrões e oportunidades de participação ofertadas, verifícam-se as consultas públicas, por meio do qual um membro do executivo solicita contribuições (geralmente por email ou carta) da sociedade acerca de determinado conjunto de temas. No segundo caso, além das possibilidades de envio direto de mensagens e o "Fale com o Deputado", são realizadas enquetes, sondagens de opinião, bate-papo e fóruns online envolvendo cidadãos e parlamentares.

Miola (2011) analisa o potencial deliberativo de um dos fóruns desse portal, ofertado pela Comissão de Legislação Participativa (CLP). Reunindo 59 participantes, o fórum deu abertura para avaliação dos trabalhos desempenhados pela CLP, fortalecendo canais de mediação entre tomadores de decisões e a sociedade. A organização do fórum a partir de perguntas aber- 
tas, a apresentação de informações complementares e a presença da moderação foram importantes para a participação e deliberação, mas faltaram orientações sobre regras de conduta, critérios para moderação e publicação das mensagens. Argumentos de representação do governo tendiam a obter maior validação em comparação com os demais participantes, sendo menor a interação entre cidadãos.

Essas experiências podem ser divididas em duas categorias: na primeira, são realizadas por meio de iniciativas iniciadas mantidas e gerenciadas por órgãos governamentais - numa perspectiva top-down, ou from above. O segundo tipo seria marcado pela autonomia em relação a esse poder - bottom up ou from below (COLEMAN e BLUMBER, 2009). Os autores consideram benéfica a independência dos projetos de democracia digital, tendo como premissa principal a oposição de interesses entre as concepções do poder administrativo e dos interesses da sociedade. Contudo, o fato do poder público assumir responsabilidade referente à estimulação, organização e mediação de tais ferramentas não é necessariamente um obstáculo: o comprometimento explícito das entidades governamentais seria uma condição para que as contribuições da população local possam ter a chance de influenciar os processos de tomada de decisão política e ter impactos concretos nos processos de planejamento. Assim, para os autores é recomendável que representantes dos governos locais forneçam a essas comunidades virtuais informações relacionadas a projetos e programas, para que os cidadãos possam participar com sugestões, informações adicionais, contestações.

Por outro lado, Coleman e Blumber (2009) enfatizam que debates democráticos só funcionam bem dentro de regras gerais que garantem um processo consistente de deliberação democrática, para que a racionalidade comunicativa possa se desenvolver. Recomendam o envolvimento de mediadores neutros, cuja função principal seria de interferir em casos de conflitos extremos, garantir a respeitabilidade e etiqueta entre os participantes e buscar promover a interatividade no processo deliberativo. A discussão deve ser impulsionada pelas preocupações dos cidadãos, e não por fatores financeiros ou poder administrativo (DALHBERG, 2001; COLEMAN \& BLUMBER, 2009).

\subsection{0 caso da Rebal21}

A Rebal21 é uma rede online que reúne participantes de processos de Agenda 21 de diversos estados, além de simpatizantes do tema e profissionais que atuam na promoção desse tipo de processo, por excelência, par- 
ticipativo. Fundada há 7 anos, desde 2009 a rede hospeda perfis, grupos de discussão virtuais e documentos de referência hospedado na plataforma Ning. Em fevereiro de 2013, a rede contabilizava 2310 membros inscritos no rebal21.ning.com, responsáveis pela postagem de 3916 fotos e 300 vídeos. Há possibilidade de postar informações em um blogs geral da rede, sendo que na mesma data tinham foram contabilizadas 904 postagens. A rede permite ainda a divulgação de eventos, tendo sido 360 cadastros.

A moderação da rede é realizada por representantes da Subcoordenação de Agenda 21 ligada à Secretaria de Meio Ambiente do Estado do Rio de Janeiro. A rede conta ainda com a presença de outros representantes governamentais - corpo técnico envolvido nos trabalhos com processos de Agenda 21 no Brasil - participantes de processos de Agenda 21 em andamento, e ainda outros participantes, que não são envolvidos com nenhum processo de Agenda 21 Local.

A maior parte da atividade na Rebal21 ocorria por meio das discussões realizadas nos 120 grupos de discussão, que na rede são enunciados como "Iniciativas dos membros e páginas dos grupos da Agenda 21 Local no Brasil". A realizada dos títulos e descrições de cada grupo permite dividi-los em três tipos: (a) grupos de discussão online ligados a processos Agenda 21 em andamento; (b) grupos de trabalho, com o objetivo de integrar participantes em torno de objetivos e ações comuns; (c) temáticos, voltados à discussão de assuntos pertinentes temas ligados à Agenda 21. Os grupos podem ser criados por qualquer participante, com a autorização da moderação. As mensagens podem ser postadas sem qualquer aprovação prévia da moderação.

As categorias de análise foram propostas para a análise das mensagens trocadas nos grupos procura respeitar a noção de argumentação em ambientes online proposta por Dahlberg (2001), e considerando adaptando categorias propostas por Jensen (2003), para analisar grupos deliberativos a partir de como os atores se relacionam ao debate, identificando: (a) a pertinência da mensagem; (b) a continuidade dada pelos outros participantes; (c) a abertura quanto à sua identidade; (d) o tom (agressivo ou respeitoso); (e) a reciprocidade e (f) a argumentação, perceptível na apresentação de justificativas ou validações (SAMPAIO, MAIA \& MARQUES, 2010; MIOLA, 2011).

Foram selecionados para análise os quatro grupos da REBAL21 que apresentavam o maior número de participantes cadastrados, assim como o maior número de mensagens trocadas entre os participantes. Em todos os grupos escolhidos, e onde se verifica tanto a presença de mensagens dos criadores 
de cada grupo quanto do perfil "Moderadores da Rebal”. A análise das informações fornecidas como subsídio à participação dos cidadãos na Rebal21 ocorreu em dois âmbitos: subsídio à argumentação dos participantes e informações relacionadas ao funcionamento do grupo, contemplando possibilidades da rede e sua dinâmica de participação.

As informações fornecidas na rede são abundantes e facilmente acessáveis, principalmente no que diz respeito ao histórico da Rebal21, os documentos que de referência desde sua criação, e informações que tenham papel relevante no provimento de subsídios à participação e ao cultivo de habilidades cívicas. Na página principal, o usuário tem acesso ao seu próprio perfil Ning (atualizações recentes e mensagens pessoais) e a outras redes relacionadas à mesma temática (tópico "Redes Irmãs"). Em "Rebal Virtual" é possível acessar tópicos indicados pela moderação, de modo a facilitar a navegação. Há ainda caixas de conteúdo específicas para postagem dos blogs e outra para as atualizações dos de tópicos de discussão (cujo envio de mensagens não está ligado ao pertencimento nenhum dos grupos de discussão), chamado "Salas de Debate".

Quanto ao fornecimento de informações e regras para participação, a Rebal21 apresenta objetivos, regras e documentos fundantes da rede disponíveis a partir da página inicial, "Dicas para navegar na Rebal”, disponível em um campo específico disponível a partir da página principal, que orienta sobre a utilização da rede e suas ferramentas. No caso dos grupos de discussão, é colocado que cada um deve ter uma temática específica. O criador é tido como responsável pela manutenção e existência, e grupos inativos são arquivados pela moderação no campo "Documentos".

É possível acessar a "Carta de Princípios da Rebal”, um documento que trata dos principais princípios da Agenda 21, e coloca regras gerais para atuação na rede. Dentre as orientações, consta que na rede não deve haver discriminação por ideologias, partidos políticos, natureza social ou cultural, buscando respeito à diversidade. A rede deve ser constituída pelos processos de Agenda 21 Local cadastrados, para fortalecer e articular iniciativas e reunir os diversos setores e instituições. "É uma Rede plural que trabalha divergências na busca de consensos,"(...) "gerar transparência na troca e disseminação de informações e na produção de documentos e atividades conjuntas".

É destacado o caráter suprapartidário da rede, e que as informações nela produzidas são públicas, sendo a ética, a transparência e os laços de confiança são valores primordiais. "O uso da Internet como um dos instru- 
mentos geradores de participação é essencial, sendo que a Rede não deve ser confundida como um mero instrumento de comunicação digital”. Orienta-se que a participação dos usuários pode ser de cinco formas: apresentar propostas de funcionamento; apoio à gestão; produção de conteúdos; proposição de novos debates; e disseminação de informações pertinentes.

A rede apresenta uma "Biblioteca Coletiva", que dispõe de 329 documentos, organizados por 45 temas/autores, hospedada fora da plataforma Ning, no Issu.com, que permite armazenamento e visualização online do material. Essa biblioteca virtual permite o nivelamento de conhecimentos acerca do tema Agenda 21 entre os participantes. Foram registradas nos grupos analisados ocasiões em que participantes aconselharam uns aos outros a procurarem esses documentos.

\subsubsection{Análise dos grupos de discussão}

Cada grupo apresenta objetivos específicos: o "Atualização da Agenda 21 Brasil” (Grupo 1) foi criado para discussão e geração de contribuições para o processo de a revisão da Agenda 21 Brasileira; o "ELO Rebal21" (Grupo 2) se declara espaço para debates do coletivo dos grupos de Agendas 21 Locais do Estado do Rio de Janeiro; o “Agenda 21 de Magé" (Grupo 3) e o "Agenda 21 de Belford Roxo" (Grupo 4), destinados a discutir os processos de Agenda 21 desses municípios.

Nenhum dos grupos fornece informações detalhadas sobre a dinâmica específica a ser seguida - como se dirigir uns aos outros, nem como e quando propor um novo debate ou será feita a moderação de cada grupo ou da rede como um todo - valendo as regras da Carta de Princípios. A dinâmica de envio de mensagens comporta dinâmicas de discussão assíncronas e permite espaços de intervenções discursivas com até 3000 caracteres . Os quatro grupos analisados ocorreram entre junho de 2009 e agosto de 2011, conforme o gráfico abaixo, que também mostra o fluxo de envio de mensagens: 


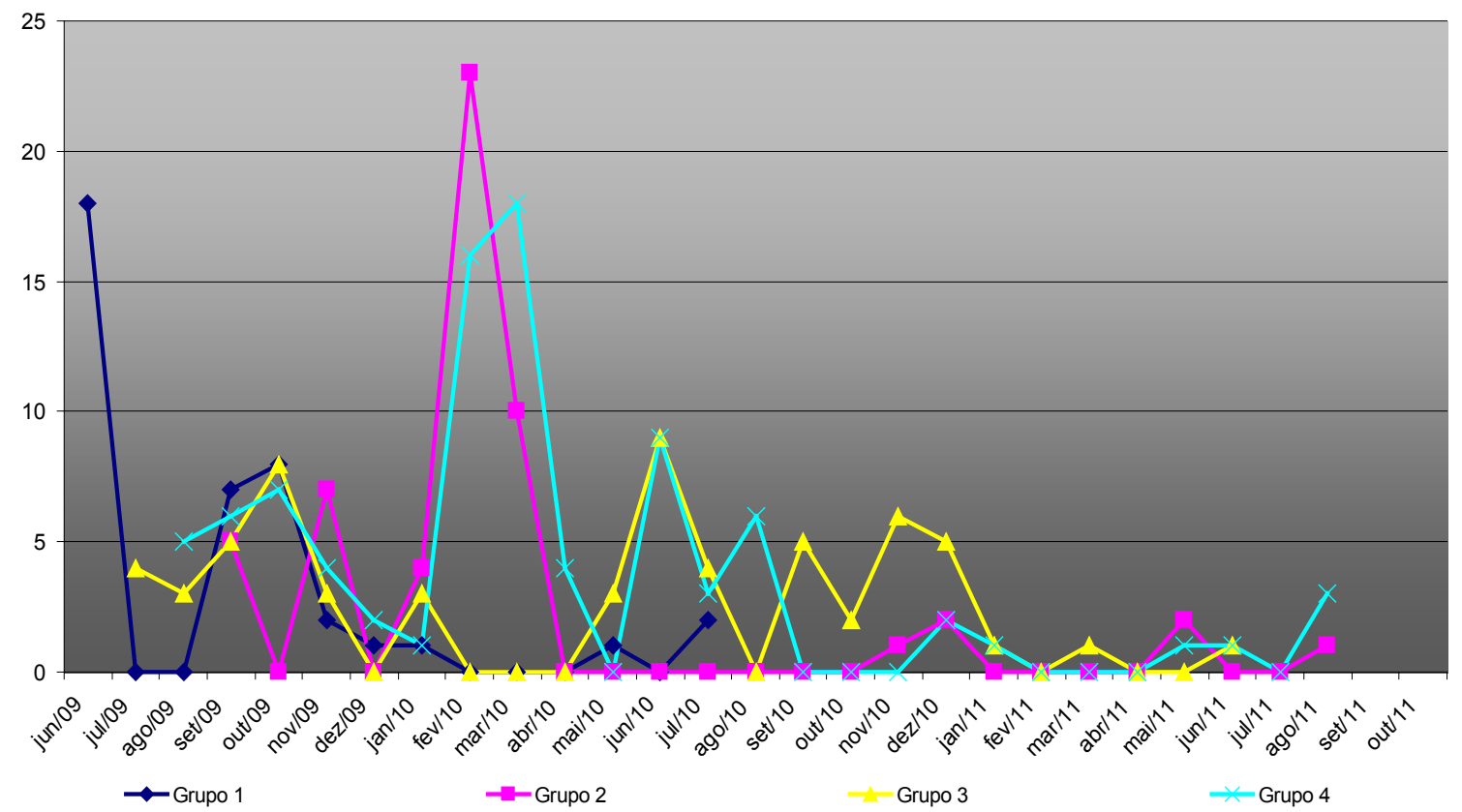

Gráfico 1: Fluxo de envio de mensagens nos quatro grupos de discussão analisados Fonte: o autor

Em cada um dos grupos, observa-se que a o fluxo de mensagens ocorreu de forma inconstante, com picos de postagens em determinados períodos. No Grupo 1, a publicação de mensagens foi mais intensa na primeira semana, observando-se picos de atividade até julho de 2010, quando a freqüência de postagens foi interrompida. No Grupo 2, houve um grande pico de publicações de mensagens em fevereiro e março de 2010, verificando-se semanas onde não houve publicação alguma. Na discussão do Grupo 3, houve um período inicial de trocas mais intensas, seguido por períodos de oscilação, com picos de atividade nos meses julho, setembro e novembro de 2010. De forma semelhante, nas discussões no Grupo 4 há oscilações com picos em fevereiro, março, junho de agosto de 2010, havendo meses sem mensagem trocada.

Em nenhum dos grupos foi colocado, a priori, se os mesmos seriam permanentes ou se teriam duração delimitada, tendo três dos grupos cessado atividade por falta de mensagens trocadas entre os participantes. Apenas no Grupo 1 houve uma comunicação formal a discussão por parte do perfil moderador da Rebal21 e criador do grupo - agradecendo a participação de todos e dando por encerrada a discussão. Percebe-se que a duração da discussão pode variar de acordo com o envolvimento das pessoas, mas é recomendável a mesma seja evidenciada, seja por tempo ou por cumprimento de objetivos. Embora seja previsto pela moderação, em nenhum dos casos houve arquivamento das discussões, até a finalização da análise. 
Em relação ao perfil ${ }^{3}$ dos participantes de cada grupo, cabe ressaltar que, dos 74 perfis que postaram mensagens em todos os quatro grupos, apenas 1 deles não revelava abertamente uma identidade (nome, foto e dados pessoais, embora não se tenha como avaliar a veracidade de todos os dados declarados). Mesmo nesse caso, outros participantes se referiram a ele pelo nome, dando a entender que o conhecem. $\mathrm{Na}$ análise dos perfis, considerou-se o grau de proximidade da representação governamental em sua relação com o potencial para influenciar políticas públicas - ou de vinculação com processos de Agenda 21. Os membros dos grupos foram divididos em quatro categorias, sendo a distribuição da participação disposta no gráfico abaixo:

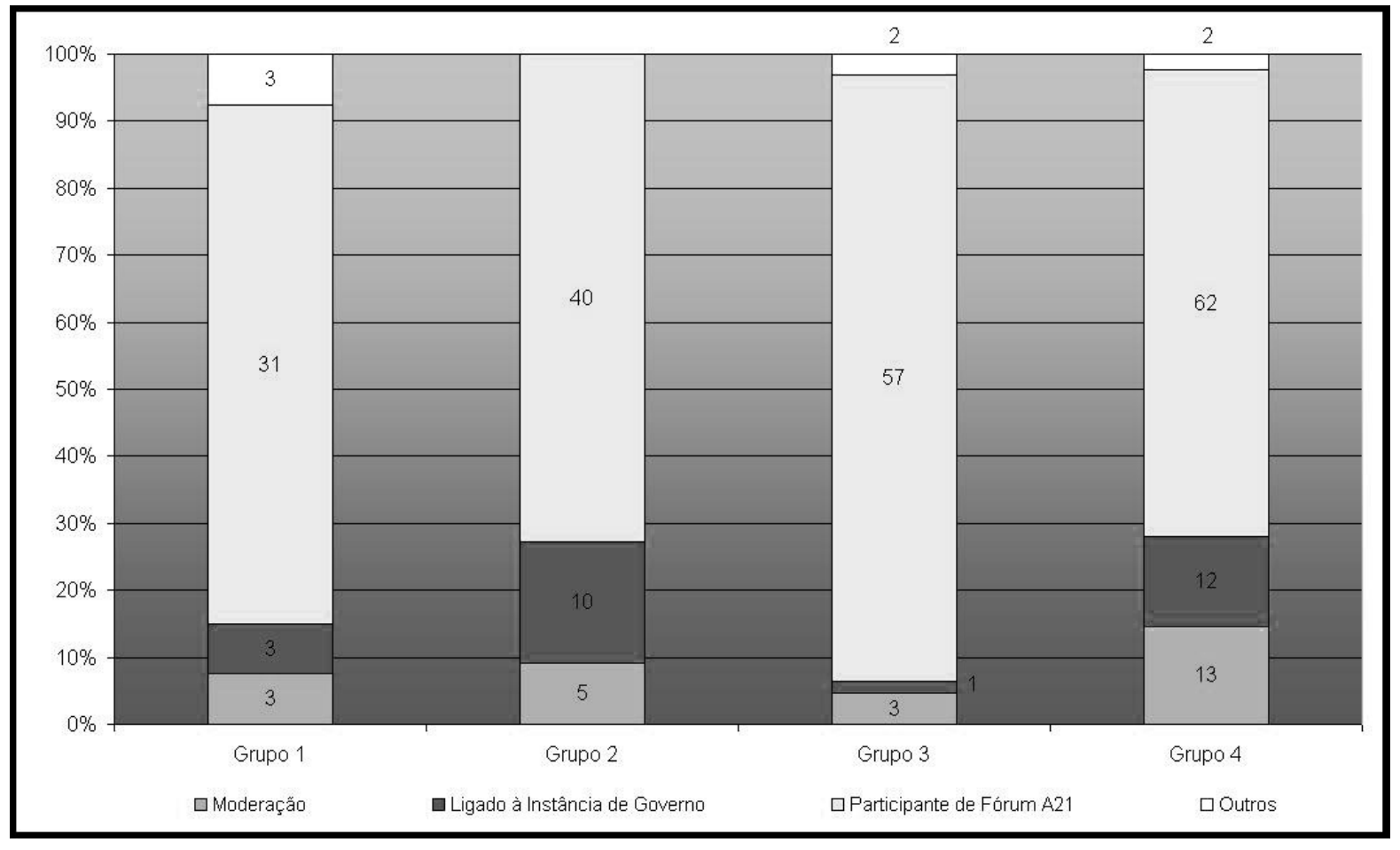

Gráfico 2: Distribuição de perfil dos participantes por grupo Fonte: o autor

Percebe-se que dos participantes dos quatro grupos é declaradamente ligado a processos de Agenda 21, que é declarado na Carta de Princípios da Rebal como o objetivo fundamental da rede. Nos grupos 2 e 4 de Belford Roxo, houve maior participação de perfis ligados ao corpo governamental,

3 A análise considerou como critério de perfil: (a) Moderação da Rede (representante governamental); (b) Diretamente relacionado ao corpo governamental; (c) Participantes de processos Agenda 21 em andamento; (d) outros participantes que não fazem parte de nenhum fórum offline acerca do tema. Os dados foram consolidados a partir de informações fornecidas no perfil dos participantes. 
principalmente funcionários do Estado do Rio de Janeiro. Contribuições desse tipo de participante centraram em prestar informações técnicas sobre a discussão que estava sendo travada ou dar avisos - geralmente sobre eventos e reuniões presenciais - aos participantes do grupo.

Houve envolvimento de representantes governamentais relacionados aos processos de Agenda 21 no debate de forma ativa, diferentemente de se colocar meramente na posição de webmasters, tanto o perfil Moderadores da Rebal quanto participantes que constituem corpo técnico governamental tiveram participação significativa nos grupos analisados. A frequência de atuação do perfil de moderador da rede foi baixa em três dos grupos, tendo se limitado a responder a questionamentos diretos feitos pelos outros participantes, seja quanto à gestão da rede como também em ocasiões onde foi pedido posicionamento da Subcoordenação de Agenda 21 do Estado do Rio de Janeiro. No Grupo 4, houve posicionamento, enquanto representação da Subcoordenação, em relação aos temas discutidos e à qualidade do debate:

Comentário de Moderadores da Rebal em 26 de março 2010 às 21h22min:

\begin{abstract}
Ninguém responde apesar de que este fórum é o que tem mais cadastrados na REBAL? Talvez não seja só o fato de não estarem a fim de trabalhar. Talvez não compreendem a ferramenta Ning. Talvez sejam tímidos quando escreverem para tantas pessoas. Talvez tenham medo de falar.
\end{abstract}

A moderação sugeriu que fosse realizado um encontro presencial com os participantes para capacitação à ferramenta Ning e aos nos conteúdos da Carta de Princípios, mas não houve adesão à iniciativa por parte dos participantes.

Em relação à postura da moderação no sentido de inibir mensagens indesejáveis, agressivas ou irrelevantes - tais como os spams ou flaming (postagem de mensagens abusivas ou agressivas, conforme DALHBERG, 2001) - não foram encontradas evidências desse tipo de censura prévia da moderação nos grupos analisados. As mensagens aparecem publicamente imediatamente após seu envio - embora a moderação tenha retirado mensagens a posteriori, conforme veremos adiante.

Durante o período de análise, foi identificado que um grupo de discussão foi retirado do ar pela moderação, pois haveria duplicidade em relação a outro grupo coordenado pelos participantes do fórum Agenda 21 de Maricá. Em seu lugar a moderação criou outro grupo, Conselho Municipal de Mari- 
cá. A justificativa enviada pela moderação em 19 de janeiro a os integrantes do grupo apagado reitera, dentre outros itens da Carta de Princípios, que "quaisquer formas de comunicação acusatórias onde não se encontrem fundamentos serão apagadas da REBAL".

\subsubsection{Análise do conteúdo das mensagens trocadas}

A análise do conteúdo das mensagens revela também aspectos ligados à elaboração e apresentação dos argumentos. Com relação ao design dos grupos para deliberação pública, cabe ressaltar o formato aberto de todos eles, de modo a não fechar a discussão em um único tema, e de não estar orientado apenas para a produção de conclusões simplesmente positivas ou negativas sobre os temas abordados. No total dos cinco grupos, foram geradas 248 mensagens. A Tabela 1 sintetiza o levantamento realizado, demonstrando a classificação absoluta das mensagens nas categorias, e sua distribuição percentual de acordo com o total de mensagens:

\begin{tabular}{|c|c|c|c|c|c|c|c|c|c|c|c|}
\hline \multicolumn{2}{|c|}{ Mensagens } & \multicolumn{2}{|c|}{ Grupo 1} & \multicolumn{2}{|c|}{ Grupo 2} & \multicolumn{2}{|c|}{ Grupo 3} & \multicolumn{2}{|c|}{ Grupo 4} & \multicolumn{2}{|c|}{ Total } \\
\hline \multirow{3}{*}{$\begin{array}{l}\text { Categoria } \\
\text { Pertinência }\end{array}$} & \multirow{2}{*}{$\begin{array}{c}\text { Subcategoria } \\
\text { Relevante }\end{array}$} & \multicolumn{2}{|c|}{$\begin{array}{l}\text { Número de } \\
\text { Mensagens }\end{array}$} & \multicolumn{2}{|c|}{$\begin{array}{l}\text { Número de } \\
\text { Mensagens }\end{array}$} & \multicolumn{2}{|c|}{$\begin{array}{l}\text { Número de } \\
\text { Mensagens }\end{array}$} & \multicolumn{2}{|c|}{$\begin{array}{l}\text { Número de } \\
\text { Mensagens }\end{array}$} & \multicolumn{2}{|c|}{$\begin{array}{l}\text { Número de } \\
\text { Mensagens }\end{array}$} \\
\hline & & 33 & $83 \%$ & 44 & $80 \%$ & 46 & $73 \%$ & 77 & $87 \%$ & 200 & $81 \%$ \\
\hline & Irrelevante & 7 & $18 \%$ & 11 & $20 \%$ & 17 & $27 \%$ & 12 & $13 \%$ & 47 & $19 \%$ \\
\hline \multirow{2}{*}{ Tom } & Agressivo & 0 & $0 \%$ & 8 & $15 \%$ & 3 & $5 \%$ & 13 & $15 \%$ & 24 & $10 \%$ \\
\hline & Respeitoso & 40 & $100 \%$ & 47 & $85 \%$ & 60 & $95 \%$ & 76 & $85 \%$ & 223 & $90 \%$ \\
\hline \multirow{3}{*}{ Diálogo } & Inicia um debate & 6 & $15 \%$ & 8 & $15 \%$ & 18 & $29 \%$ & 10 & $11 \%$ & 42 & $17 \%$ \\
\hline & Responde & 14 & $35 \%$ & 23 & $42 \%$ & 29 & $46 \%$ & 59 & $66 \%$ & 125 & $51 \%$ \\
\hline & Monológica & 20 & $50 \%$ & 24 & $44 \%$ & 16 & $25 \%$ & 20 & $22 \%$ & 80 & $32 \%$ \\
\hline \multirow{4}{*}{ Reciprocidade } & Progresso & 12 & $30 \%$ & 28 & $51 \%$ & 29 & $46 \%$ & 33 & $37 \%$ & 102 & $41 \%$ \\
\hline & Persuasão & 5 & $13 \%$ & 9 & $16 \%$ & 6 & $10 \%$ & 18 & $20 \%$ & 38 & $15 \%$ \\
\hline & Radicalização & 6 & $15 \%$ & 10 & $18 \%$ & 21 & $33 \%$ & 23 & $26 \%$ & 60 & $24 \%$ \\
\hline & Sem Reciprocidade & 17 & $43 \%$ & 9 & $16 \%$ & 7 & $11 \%$ & 15 & $17 \%$ & 48 & $19 \%$ \\
\hline \multirow{4}{*}{ Argumentação } & Validação externa & 19 & $48 \%$ & 15 & $27 \%$ & 27 & $43 \%$ & 35 & $39 \%$ & 96 & $39 \%$ \\
\hline & Validação Interna & 6 & $15 \%$ & 11 & $20 \%$ & 14 & $22 \%$ & 16 & $18 \%$ & 47 & $19 \%$ \\
\hline & Alegação & 13 & $33 \%$ & 27 & $49 \%$ & 19 & $30 \%$ & 31 & $35 \%$ & 90 & $36 \%$ \\
\hline & Sem argumentação & 2 & $5 \%$ & 2 & $4 \%$ & 4 & $6 \%$ & 7 & $8 \%$ & 15 & $6 \%$ \\
\hline
\end{tabular}

Tabela 1: Classificação das mensagens trocadas nos grupos por categorias Fonte: o autor

Quanto à pertinência das mensagens para o debate, na avaliação realizada das mensagens enviadas dos grupos da Rebal21, optou-se por considerar relevantes quaisquer mensagens que tivessem alinhamento com temas ligados à proposta de cada fórum e aos processos de Agenda 21. Por exemplo, mensagens que discutiam a importância da implantação de um determinado serviço público foram consideradas relevantes, mas comentários ou 
"pensamentos" vagos sustentabilidade - que não diziam diretamente respeito à discussão realizada no momento - foram considerados irrelevantes, como no exemplo abaixo:

Grupo 4 - Comentário de R.C. em 31 de janeiro 2011 às 20:54min:

Precisamos abolir a palavra lixo, $\mathrm{p} /$ avançarmos no processo de sustentabilidade de fato. Lixo não existe. Precisamos reciclar o conceito. Porque as maquinas produzem sem preconceito.

Outro critério para julgamento foi a pertinência atribuída pelos próprios participantes daquele fórum, dando continuidade ou não ao tópico proposto.

Nos quatro grupos analisados, a grande maioria das mensagens trazia alguma contribuição relevante para a discussão que estava sendo traçada, num total de $81 \%$ das mensagens trocadas nos quatro grupos. No Grupo 3, no qual o percentual de relevância ficou em $73 \%$, esse resultado explica-se pela recorrência de um participante específico, J.R., que continuamente encaminhava mensagens - principalmente em comentários sobre a instalação de um empreendimento petroquímico nas proximidades da cidade - mas uma relação mais estreita com os temas que estavam sendo discutidos.

A análise do tom das mensagens parte da constatação de que, nos fórum de discussão online, a impessoalidade acaba por favorecer a violação de normas de boa conduta por parte dos participantes, resultando em insultos ou ofensivos (DAHLBERG, 2001; MIOLA, 2011). O percentual de mensagens de tom agressivo não superou $15 \%$ em nenhum dos quatro grupos analisados, sendo que no total apenas 10\% dos comentários se enquadrou nessa categoria. Essas ocorrência geralmente tendiam a desqualificar a iniciativa de diálogo proposta, ou apresentava algum tipo de frustração em relação ao andamento da discussão, como no exemplo:

Grupo 4 - Comentário de J.C. em 25 de março 2010 às 21:47min:

Ninguém fala nada NEM UM BOM DIA. Se o Papai C. MORRER, FERROU A MARIOLA. ISSO NÃO É COLEGIADO NEM AQUI E NEM EM LUGAR NENHUM DO UNIVERSO. VOU TORCER PARA QUE ELE NÃO MORRA, POIS ELE É ROCK N' ROLL. RECICLAAAÇÃO AMBIENTALISMO DE AÇÃO.

A moderação tratou o comentário da seguinte forma:

Grupo 4 - Comentário de Moderadores da Rebal em 26 de março 2010 às 1:46min: 
Preocupante a provocação do amigo J.C. Não que eu ache que as provocações não sejam necessárias a rede. Particularmente tenho a certeza que as redes sociais só sobrevivem e até mesmo ganham sentido, quando os membros do coletivo provocam discussões e são provocados a tecer comentários e a construir conhecimento. No entanto não posso concordar que estas provocações não tenham profundidade ou mesmo sirvam para testar o grau de mobilização deste determinado coletivo (...).

Entre os grupos analisados, foi identificado um único caso em que uma mensagem foi apagada pela moderação, no sentido de eliminar comentários agressivos. Essa ocorrência chegou a ser discutida no fórum e comentada pela moderação:

Grupo 4 - Comentário de T.G. em 29 de junho 2010 às 21:22min:

O QUE É ISSO? NÃO ESTOU TENDO DIREITO DE RESPOSTA, ENTÃO PORQUE APAGARAM A MINHA RESPOSTA QUE LHES ENVIEI? NÃO ESTOU ENTENDENDO OS SENHORES MODERADORES DA REBAL.

Grupo 4 - Comentário de Moderadores da Rebal em 29 de junho 2010 às 16:55min:

Espero que entendas que não se trata de direito de resposta. Apagamos os comentários que consideramos ofensas pessoais e não uma proposta de consenso. Agradeço a compreensão e sugiro chegarem a um consenso sobre o caso que continua no Fórum de Discussão aberto por você "Qual será o fim dos pneus?" Entenda que estamos apenas seguindo nossa Carta de Princípios ok? Abraço.

Nesse caso a moderação cumpriu o papel destacado na Carta de Princípios, de evitar mensagens agressivas.

A observação da qualidade do diálogo entre os participantes dos grupos também guarda relação a deliberação pública. Como coloca Dahlberg (2001), a troca de razões ocorre quando a participação é marcada pela reflexividade, ou seja, que os sujeitos analisem seus pontos de vista e valores de forma crítica. Embora seja difícil determinar quando de fato esse tipo de avaliação crítica ocorre nos indivíduos, optou-se pela classificação utilizada por Miola (2011): (a) esforço em iniciar um debate ou (b) responder a um outro debatedor (c) e mensagens onde o diálogo não é buscado.

Averiguou-se que a ocorrência de diálogo entre os participantes se de 
forma diferente em cada um dos grupos. De forma geral, cerca de metade (51\%) das mensagens trocadas apresentava algum tipo de resposta ou contribuição a algo que já havia sido colocado em discussão. Ressalta-se no Grupo 1 , em que cerca de metade dos comentários colocados foram classificados como monológicos porque não respondiam a nenhum outro participante, nem foram objeto de resposta posterior. Essa recorrência de mensagens monológicas também predominou no Grupo 2. Dois participantes, J.C. e J.G, recorreram em mensagens que não demonstravam intenção de iniciar ou contribuir com o debate, sendo responsáveis por mais da metade dos $44 \%$ das mensagens monológicas. Em Grupo 3, J.R. foi responsável por 23 das 63 mensagens trocadas, também foi responsável por 8 das 16 das mensagens monológicas registradas.

No Grupo 4, 11\% das mensagens pretendia iniciar novo debate ou subtema, enquanto a maioria das mensagens (66\%) eram contribuições ao debate existente. É válido ressaltar que 12 das 65 mensagens classificadas resposta foram enviadas pelo perfil Moderadores da Rebal, que atuou de forma ativa, satisfazendo a questionamentos. Percebeu-se que os participantes interagiram com esse perfil mais do que uns com os outros, representando o desejo de tratar com a representação governamental.

Comentário de T.O.G. em 3 de julho 2010 às 20:26

O que é engraçado é vejo pelas mensagens que todos estamos lutando em encontrar soluções, sei que tem políticos na REBAL, agora eles nem se quer para dar uma resposta de alguma coisa. Me desculpe, mais se não falarmos como saberão dos problemas? Não estou aqui para ficar bajulando ninguém,apenas estou colocando um assunto em que é mínimo, já que essa área ambiental tem milhões de problemas.É triste a gente se formar em uma área e ver tanta coisa errada e ainda ser ignorada.

A reciprocidade, segundo Jensen (2003), pode ser percebida na ocorrência de mensagens onde há progresso (quando o participante reflete sobre outra postagem com novas informações ou argumentos) ou persuasão (quando há reiteração de pontos que já tenham sido defendidos) ou radicalização, "quando o usuário reage negativamente à outra postagem e radicaliza seu ponto de vista anterior, não estando aberto a outras possibilidades" (SAMPAIO, MAIA e MARQUES, 2010, p.458). Abaixo estão exemplos de cada (persuasão, progresso e radicalização) respectivamente:

GRUPO 3 - Comentário de J.S em 28 de outubro 2009 às 12:03 
Meu caro R., concordo que para abordarmos creio ser necessário um aprofundamento do que chamamos desenvolvimento sustentável, em face dos mega projetos industriais em curso e previsto em nossa região, e desenvolvimento industrial demais para uma população tão pobre. Não consigo vislumbrar o transbordamento de tamanha riqueza para as classes subalternas que alimenta a política em troca de cesta básica (...)

\section{GRUPO 2 - Comentário de J.G. em 23 de novembro 2009 às 22:44}

Pessoal, Como militante, pesquisadora e consultora na construção de agendas 21 escolares, me permito discordar das seguintes afirmações (...) Em primeiro lugar: as Agendas 21 Escolares não são apenas um desdobramento das agendas 21 locais. È desejável que estas dimensões se articulem e dialoguem num território, mas as agendas 21 escolares possuem uma identidade própria e muitas vezes são elas o locus onde nascem as agendas 21 locais. Esta afirmação desempodera todo um discurso e ação que atores sociais diversos vínhamos fazendo, inclusive na CPDS, com relação à necessidade do MMA definir indicadores para estas agendas.

GRUPO 4 - Comentário de R.C. em 1 de julho 2010 às 9:27

Referente aos pneus eles são uma micro gota no oceano (...) a legislação é completamente contra a reciclagem de fato. Só não enxerga quem não entende, ou é mal intencionado, ou os dois.

Em quase quinto do total de mensagens dos grupos (19\%), não foi identificado nenhum indício de reciprocidade, o que foi mais marcante nas mensagens trocadas no fórum Grupo 1 (43\%). Nos outros três grupos, esse percentual não chegou a $20 \%$ das mensagens. Assim, pode-se inferir que a maioria dos participantes respondeu de forma recíproca, seja apresentando novos argumentos, concordâncias ou discordâncias, o que pode ter sido favorecido por todos terem acesso ao histórico de mensagens trocadas, assim como pela obrigatoriedade de identificação nos perfis públicos nas postagens.

Cerca de $40 \%$ de todas as mensagens trocadas nos grupos analisados refletiam o progresso da discussão, no sentido de contribuir com novas informações ou pontos de vista. As mensagens persuasivas permaneceram entre $10 \%$ e $20 \%$ em cada grupo. No Grupo 4 verificou-se maior índice de mensagens persuasivas em relação aos outros grupos, principalmente devido às tentativas de convencimento por parte de um dos participantes, R.C., tam- 
bém responsável pela maioria das radicalizações identificadas.

Em relação à como foi desenvolvida nos grupos a argumentação ${ }^{4}$ propriamente dita, procurou-se identificar se os argumentos possuíam elementos de (a) validação externa (participante baseia-se prioritariamente em informações de fontes externas); (b) validação interna (apresentação de ponto de vista e valores pessoais); e também (c) alegações, que não apresentam qualquer tipo de validação com fatos ou pontos de vista, (JENSEN, 2003; SAMPAIO, MAIA e MARQUES, 2010), tendo sido identificado, por exclusão, mensagens que não apresentaram indícios argumentativos (MIOLA, 2011).

A análise permite identificar que no total das mensagens trocadas nos grupos houve uma um equilíbrio entre participantes utilizando de fontes externas para sustentar seus argumentos - validação interna (39\%) - e aqueles que afirmaram seus pontos de vista sem qualquer justificativa - alegações (36\%). É relevante destacar nos grupos a presença de 15 mensagens (em cada um) que não apresentavam nenhum tipo de posição ou argumentação - geralmente também não buscaram o diálogo, nem apresentaram posições definidas sobre a discussão - geralmente divulgações de eventos ou informativos, como no exemplo abaixo:

Grupo 3 - Comentário de J.R. em 30 de novembro 2010 às 14:49

CONVITE - Apresentação de Projetos de Turismo para Magé. Você está convidado a assistir. DATA: 01 de dezembro; HORÁRIO: 15:00 horas; Local: Auditório da Secretaria de Turismo e Meio Ambiente

\section{CONCLUSÕES}

De forma geral, constatou-se que a Rebal21 funciona fator de integração e difusão de conhecimentos entre os participantes e favorece novas alternativas de participação política. Embora não consiga sozinha propiciar solução para os entraves de conduzir um processo deliberativo e democrático de diagnóstico participativo, como é um processo Agenda 21 (a rede não tem esse objetivo), ela permite que cidadãos envolvidos se associem,

4 Foram considerados como validação externa os comentários que apresentaram em suas justificativas fontes externas. Os comentários classificados como validação interna os comentários onde os pontos de vista foram justificados apenas por valores ou testemunho pessoais. Foram tratados como legações aquelas mensagens que continham posicionamentos, mas não se enquadravam nas outras categorias. 
troquem informações e debatam questões de interesse comum, antes que essas idéias sejam levadas a uma instância decisória formalmente instituída.

Evidenciou-se que, por um lado, a ligação com o poder público responsável pela criação e moderação do site, hospedando o debate pode, em certas ocasiões, ser um indicador importante para qualificar a discussão - tanto pela inserção de informação qualificada quanto pela possibilidade de evitar comentários agressivos e indesejáveis. Análise não apontou nas discussões ligações ideológicas com partido ou com a instância governamental que criou a rede o governo que criou a rede. Assim, o discurso foi impulsionado mais pelas preocupações dos cidadãos do que por outros fatores.

Contrariando a recomendação normativa de que a moderação deve manter-se neutra e interferir apenas em conflitos extremos, o perfil moderador da rede, mais do que mero webmaster, mostrou-se ativo e participante das discussões, buscando promover a interatividade no processo das discussões e o alinhamento com a proposta da rede. Nos casos em que comentários foram excluídos houve uma justificativa, no sentido do alinhamento com a Carta de Princípios da rede.

Os grupos analisados, de modo geral, seguiram regras gerais para um bom funcionamento, em que cada participante potencialmente teria direito de introduzir e questionar qualquer afirmação. A maioria das mensagens trocadas era pertinente à discussão, em tom respeitoso e, em uma parcela significativa, guardando alguma relação dialógica com a discussão em andamento. Isso favorece a análise crítica dos argumentos e valores apresentados publicamente, de forma que se um participante possa compreender o argumento da perspectiva do outro. Entretanto, as instruções iniciais dos grupos foram muito abertas, e isso pode ter prejudicado a argumentação orientada para um objetivo final de chegar a conclusões capazes de orientar decisões offline.

Percebeu-se ainda que a possibilidade de interação direta com a representação estatal tende a atrair mais o público em comparação com outros participantes, como enfatiza Miola (2011). Isso pode ser reflexo da vontade dos participantes de influenciar mais diretamente efetivamente ter impactos concretos nos processos envolvidos.

É preciso reconhecer, contudo, que a aplicação de critérios normativos para avaliação da participação e deliberação pode desconsiderar detalhes importantes que a experiência pode apresentar. Para isso, faz-se importante uma análise da experiência dos usuários desses grupos - especialmente os dois relativos a processos Agenda 21 em andamento - de modo a esta- 
belecer conexões entre as discussões online e suas possíveis inflexões nos contextos concretos aos quais eles se referem.

É válido ainda considerar que a manutenção do acesso aos arquivos dos debates, mesmo quando encerrados, pode ser útil como fonte de consulta do público e dos próprios agentes estatais e funcionar como um registro dos posicionamentos discutidos num dado momento. Da mesma forma, os arquivos da biblioteca mantida exercem papel importante ao divulgar um rico acervo de informações e documentos digitalizados a respeito de processos Agenda 21, cidadania e direitos humanos. Assim, conclui-se que, mesmo nos casos em que não houve grande reciprocidade e reflexividade, a rede e seus grupos são importantes do ponto de vista da participação e aprendizado dos usuários.

\section{REFERÊNCIAS}

ALDÉ, A. "O internauta casual: Notas sobre a circulação da opinião política na internet". Revista USP, v. 91, p. 24-41, 2011.

ARENDT, H. Verdade e Política. Trad. Manuel Alberto. Lisboa: Relógio D’Água, 1995.

BARDIN, L. Análise de Conteúdo. Lisboa: Edições 70, 1998.

CHADWICK, A. Internet Politics. States, Citizens and New Communications

Technologies, New York: Oxford University Press, 2006.

COLEMAN, S.; BLUMLER, J. The internet and democratic citizenship: theory, practice and policy. New York: Cambridge University Press, 2009.

DAHLBERG, Lincoln. Extending the public sphere through cyberspace: The case of Minnesota E-democracy. First Monday, Volume 6, Number 3 - 5 March 2001. Disponível em http://ojphi.org/htbin/cgiwrap/bin/ojs/index.php/fm/article/view/838/747 Acesso em 01/09/2011.

HABERMAS, J. Direito e Democracia - entre facticidade e validade. Vol II. Tradução Flávio Beno Siebeneichler. Rio de janeiro: Tempo Brasileiro, 1997. p. 9-121.

JENSEN, J. L. Public Spheres on the Internet: Anarchic or Government-Sponsored - A Comparison. Scandinavian Political Studies, 26 (4), 2003, p. 349-374.

MAIA, R. C. M. "Redes cívicas e internet: efeitos democráticos do associativismo". In: GOMES, W.; MAIA, R. C. M. Comunicação e Democracia: problemas e perspectivas. São Paulo: Paulus, 2008, p.327-348.

MARQUES, F. P. J. A. Participação, instituições políticas e Internet: um exame dos canais participativos nos portais da Câmara e da Presidência do Brasil. Intercom - Revista Brasileira de Ciências da Comunicação, v. 33, n. 1, 2010.

MIOLA, E. 2011. "Iniciativas institucionais de deliberação online: um estudo do fórum de 
discussão do portal da Câmara dos Deputados". In: MAIA, Rousiley; GOMES, Wilson \& MARQUES, Francisco P. Jamil (orgs.). Internet e participação política no Brasil. $1^{\text {a }}$ ed. Porto Alegre: Sulina.

SAMPAIO, R. C.; MAIA, R. C. M. \& MARQUES, F. P. J. A. "Participação e deliberação na internet: um estudo de caso do Orçamento Participativo Digital de Belo Horizonte". Opin.

Publica. 2010, vol.16, n.2, pp. 446-477.

SANTAELLA, L.; LEMOS, R. Redes Sociais Digitais: a cognição conectiva do Twitter. São Paulo: Paullus, 2010.

SANTOS, B. S; AVRITZER, L. “Para ampliar o cânone democrático”. In: Santos, B. S. (org.). Democratizar a democracia - os caminhos da democracia participativa. Rio de Janeiro: Civilização Brasileira, 2002. p.39-82.

SILVA, S. P. Estado, democracia e Internet: requisitos democráticos e dimensões analíticas para a interface digital do Estado. 2009. 425f. Tese (Doutorado em Comunicação e Cultura Contemporânea) Universidade Federal da Bahia, Faculdade de Comunicação.

\section{Alysson Bruno Assunção}

Alysson Assunção atua como Profissional de Comunicação Social na Petrobras desde 2009, com gestão de portífólio e de projetos de Responsabilidade Social Corporativa e Comunicação Empresarial. É mestre em Comunicação Social pela Universidade do Estado do Rio de Janeiro (2013), especialista em Jornalismo Literário (ABJL-SP - 2008) e Psicologia Clínica (IBAC-DF - 2008). Possui graduação em Comunicação Social pela Universidade Federal de Goiás (2007), e Psicologia pela Pontífícia Universidade Católica de Goiás (2007). 